GSA Data Repository 2018057

\title{
Elastic geothermobarometry: corrections for the geometry of the host-inclusion system
}

\author{
Mazzucchelli M.L., Burnley P., Angel R.J., Morganti S., Domeneghetti M.C., Nestola F., \\ Alvaro M.
}

\section{COMPUTATIONAL DETAILS}

We have used a commercially available engineering package, MSC MARC/Mentat, to create and analyze 2D axisymmetric and 3D finite-element models. Another engineering software, Abaqus Standard v.2016 (Dassault Systèmes, Simulia, Providence), has been used to replicate the 3D models adopting the same simulation strategy, and cross-check for consistency in the stress calculation for those shapes that have edges and corners.

For those models that have at least one rotational axis (sphere, ellipsoids of revolution and cylinders), 2D axisymmetric models were constructed with MARC/Mentat using six-node triangular elements (element 126 in the MARC library) that have a node at each vertex and at the midpoint of each side that allows a parabolic interpolation function to be used along each edge. These models were calculated assuming an axisymmetric geometry utilizing full integration. For the other shapes, 3D models have been reproduced with both MARC/Mentat and Abaqus to check for consistency in the obtained solutions for the stress. All 3D models have at least three orthogonal mirror planes, therefore only $1 / 8$ of the selected shape was created. The resulting model consisted of about 400000 four-node linear isoparametric tetrahedral elements (element 134 and C3D10 in the MARC and Abaqus library respectively). The finished 1/8 model was then reflected through three orthogonal mirror planes and joined along the resulting inner surfaces. Material properties and boundary conditions were assigned, and then a mesh convergence analysis was performed. The models were calculated as 3D solids assuming constant dilation using full integration. The element is integrated numerically at a single point at the centroid of the element and linear interpolation 
functions are used. An iterative process was used to discretize the model with different mesh sizes. Smaller elements were used to discretize the region around and inside the inclusion while larger elements were used for the remaining part of the model (Fig. DR1). The mesh was refined in the areas with higher stress gradients until the calculated stress distribution appeared smooth. To simulate the external pressure, edge loads were applied to the external boundaries of the 2D models and face loads were applied to the 3D elements on the external boundaries of the host. MARC uses numerical integration to calculate equivalent nodal loads given the dimensions of the area over which the distributed load is applied. Face loads are integrated using a single integration point at the centroid of the element face to which they are applied. Face and edge loads are assumed by MARC to have the same units as the elastic moduli (i.e. GPa). Boundary conditions were placed on the appropriate edges and faces of the models to avoid rigid body rotation and translation in the $\mathrm{x}, \mathrm{y}$ and $\mathrm{z}$ directions.

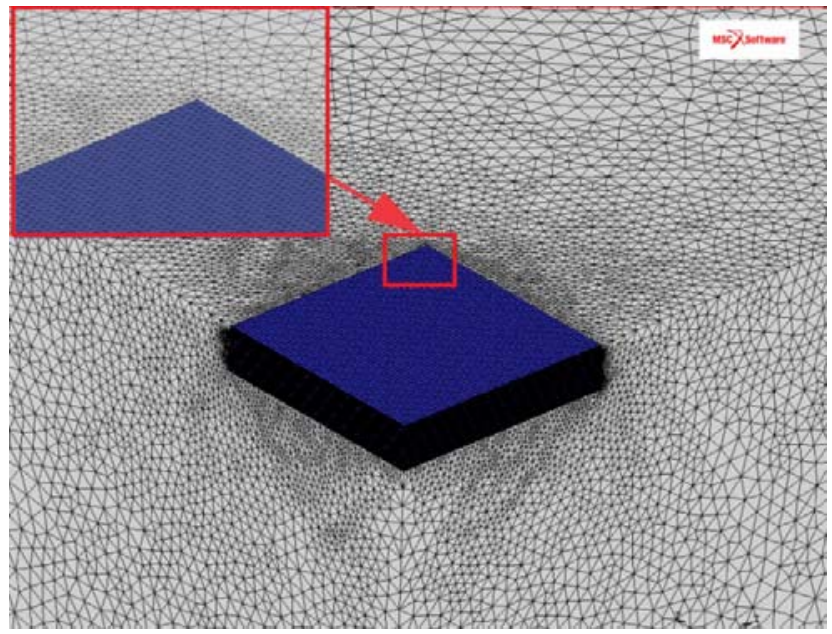

Figure DR1. 3D Finite element meshes of a prismatic inclusion with aspect ratio 1:5:5 (blue region) and of the surrounding host. Only an eighth of each model is shown. The full model is obtained by reflection through three orthogonal mirror planes, as described in the text. 


\section{ELASTIC PROPERTIES}

As discussed in the main text, the calculation of the remnant pressure on the inclusion were performed using linear elasticity (i.e. neglecting the temperature and pressure derivatives of the moduli, $d K / d T, d K / d P, d G / d T, d G / d P)$. The properties used are reported in Table DR1.

TABLE DR1. ISOTROPIC ELASTIC PROPERTIES USED FOR THE SIMULATIONS REPORTED IN FIG. 2 AND 3 IN THE MAIN TEXT

\begin{tabular}{|c|c|c|c|c|c|c|}
\hline Mineral & $\begin{array}{c}\text { Bulk } \\
\text { Modulus, } \\
K_{0 T} \\
(\mathrm{GPa})\end{array}$ & Ref. & $\begin{array}{c}\text { Shear } \\
\text { Modulus, } \\
G_{0 T} \\
(\mathrm{GPa})\end{array}$ & Ref. & $\begin{array}{l}\text { Young's } \\
\text { Modulus, } E \\
(\mathrm{GPa})\end{array}$ & $\begin{array}{l}\text { Poisson's } \\
\text { ratio, } v\end{array}$ \\
\hline Quartz & 37.0 & Scheidl et al. (2016) & 44 & Wang et al. (2015) & 94.53 & 0.0742 \\
\hline Pyrope & 163.7 & Milani et al. (2015) & 94 & $\begin{array}{l}\text { Sinogeikin and Bass } \\
(2002)\end{array}$ & 236.7 & 0.2590 \\
\hline Diamond & 444 & Angel et al. (2015b) & 535 & $\begin{array}{l}\text { Grimsditch and } \\
\text { Ramdas (1975) }\end{array}$ & 1145.1 & 0.0702 \\
\hline Olivine & 126.3 & Angel et al. (2017b) & 78 & Abramson et al. (1997) & 194.1 & 0.2440 \\
\hline Feldspar & 55 & $\begin{array}{l}\text { Average value for alkali } \\
\text { feldspars e.g. } \\
\text { Waeselmann et al. } \\
(2016)\end{array}$ & 35 & Brown et al. (2006) & 86.63 & 0.2375 \\
\hline
\end{tabular}

The correction for the geometry for the specific case reported by Ashley et al. (2016) requires the calculation of geometrical factor $\Gamma$ at two different values of $T_{\text {end }}\left(31\right.$ and $\left.500^{\circ} \mathrm{C}\right)$. Therefore, the elastic properties to be used in the FE calculations must be evaluated at these two temperatures. The bulk modulus of almandine has been calculated with a PVT-EoS that combines data from Milani et al. (2015) and Scandolo (2016). Its shear modulus is allowed to change with temperature and pressure according to the $P$ and $T$ derivatives from Arimoto et al. (2015). The variation of the quartz bulk modulus has been evaluated with the new EoS proposed by Angel et al. (2017a), that includes an improved description of the $\alpha-\beta$ structural transition. The shear modulus of quartz has a small 
variation over T (Lakshtanov et al., 2007) which does not affect significantly the results of the calculations, and is therefore assumed to be constant. The resultant elastic parameter used for the simulations at each $T_{\text {end }}$ are reported in Table DR2.

TABLE DR2. ELASTIC PARAMETERS FOR ALMANDINE AND QUARTZ USED FOR THE CALCULATIONS OF THE GEOMETRICAL FACTOR REPORTED IN TABLE 1 IN THE MAIN TEXT

\begin{tabular}{|c|c|c|c|c|c|c|c|}
\hline \multirow{2}{*}{$\begin{array}{l}\text { Tend } \\
\left({ }^{\circ} \mathrm{C}\right)\end{array}$} & \multirow{2}{*}{$\begin{array}{c}P_{\text {end }} \\
(\mathrm{GPa})\end{array}$} & \multirow{2}{*}{$\begin{array}{c}P_{i n c} \\
(\mathrm{GPa})\end{array}$} & \multicolumn{2}{|c|}{ Almandine (host) } & \multicolumn{2}{|c|}{ Quartz (inclusion) } & \multirow[b]{2}{*}{ Geometrical factor $(\Gamma)$} \\
\hline & & & $\begin{array}{c}K_{0 T} \\
(\mathrm{GPa})\end{array}$ & $\begin{array}{c}G_{0 T} \\
(\mathrm{GPa})\end{array}$ & $\begin{array}{c}K_{0 T} \\
(\mathrm{GPa})\end{array}$ & $\begin{array}{c}G_{0 T} \\
(\mathrm{GPa})\end{array}$ & \\
\hline 31 & 0 & 0.3 & 172.54 & 94.86 & 39.03 & 44.4 & -0.094 \\
\hline 500 & 0 & 0.491 & 161.86 & 88.68 & 32.17 & 44.4 & -0.078 \\
\hline
\end{tabular}

\section{STRESS WITHIN AND AROUND THE INCLUSION}

For a spherical inclusion included in an infinite host, the analytical models (Zhang, 1998; Angel et al., 2015a) predict that: (i) in the portions of the host far away from the inclusion the stress is hydrostatic, homogeneous, and equal to the external pressure; (ii) in the host close to the inclusion the stress is deviatoric even if the pressure (defined as the negative of the average of the three normal stresses) remains equal to the external pressure; (iii) in the inclusion the stress is homogeneous and hydrostatic.

With FEM the complete stress distribution within and around an inclusion for any geometry is obtained, solving for each component of the stress tensor at any given position within the model. As an example, here we show the stress distribution calculated for a quartz (soft) and a diamond (stiff) inclusion with prismatic shape and aspect ratio 1:5:5 included in a pyrope host. In fig. DR2 is reported the stress distribution along two different sections that cut the model from the center of the system (i.e. the center of both the host and the inclusion) along the shortest (x-axis) and longest (yaxis) directions of the inclusion.

As could be expected, in the portion of the host that are not perturbed by the presence of the inclusion the stress is still homogeneous and hydrostatic. Closer to the inclusion the stress in the 
host becomes deviatoric, and the amount of differential stress developed in the host is different along the two geometrically non-equivalent directions (x- and $y$-axes). It should be noted that here the pressure is not constant and deviates from the external pressure.
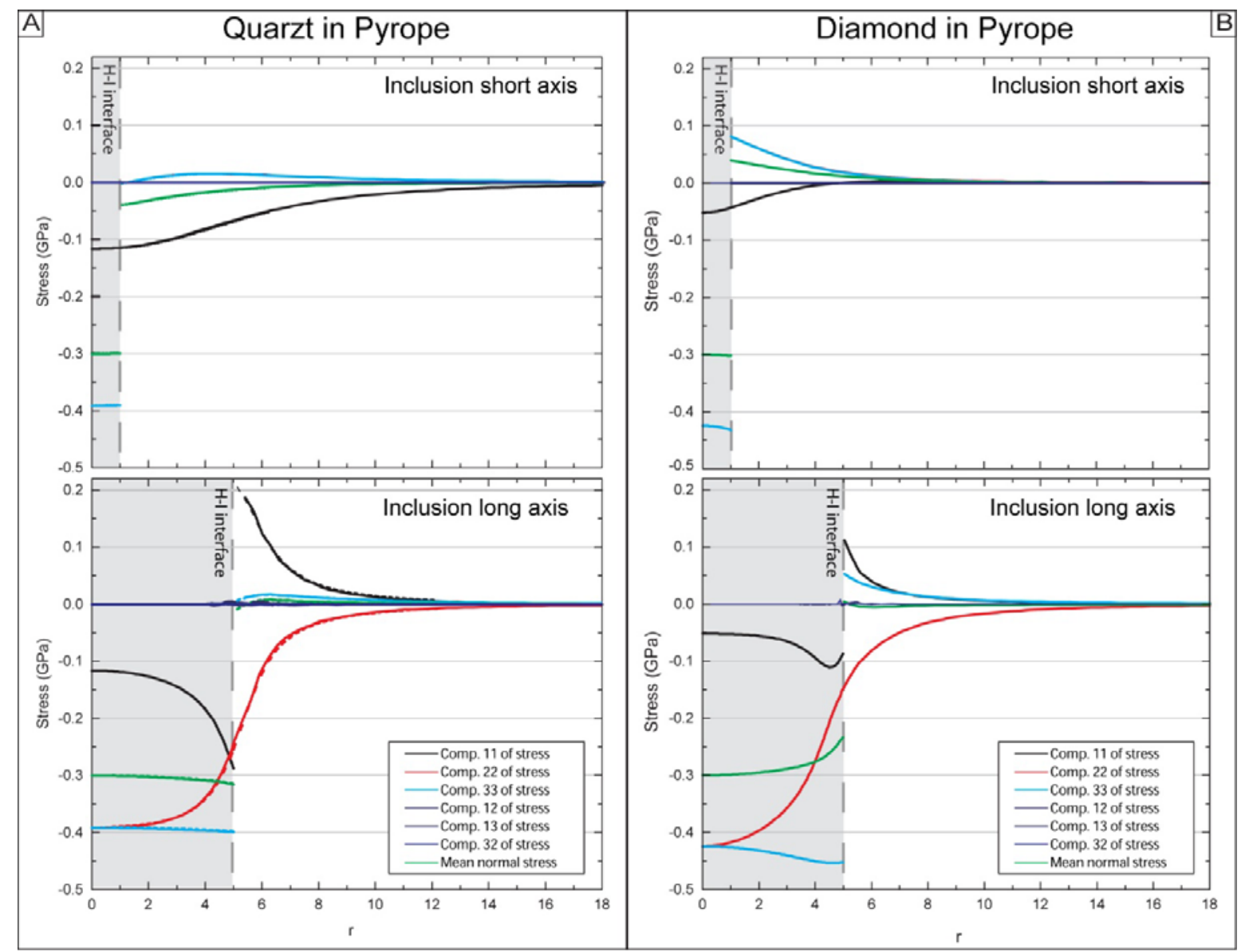

Figure DR2. Stress distribution inside and around a prismatic inclusion with aspect ratio 1:5:5. The shaded area represents the inclusion. Two cases are reported: A) quartz included in pyrope (soft inclusion in stiffer host); B) diamond included in pyrope (stiff inclusion in softer host). For both, a section along the shorter inclusion axis (x-axis of the model) and along one of the two geometrically equivalent longer inclusion axis (y-axis of the model) are shown. The stresses 
calculated with MARC/Mentat (solid lines) and Abaqus (dashed lines) always agree within 0.3\%.

Our results also show that, even when the elastic properties are isotropic, non-spherical inclusions always develop deviatoric stresses. For a quartz inclusion in garnet with a residual pressure (negative of the mean normal stress) of $0.3 \mathrm{GPa}$ and with an aspect ratio of 1:5:5, the differential stress $\left(\sigma_{\max }-\sigma_{\min }\right)$ within the inclusion can reach up to $0.22 \mathrm{GPa}$ for an ellipsoid, and $0.28 \mathrm{GPa}$ for a prism (see Fig. DR2).

The pressure, defined as the negative of the mean normal stress, is homogeneous in ellipsoids but in prisms a gradient is developed, with the "pressure" changing by $5 \%$ percent from the center of the inclusion to its surface on the longest axis (Fig. DR2 and DR3). Fig. DR2 shows that for the same shape of the inclusion under the same $P_{\text {inc }}(0.3 \mathrm{GPa})$, a stiff inclusion in a softer host, such as diamond included in pyrope, develops a much larger differential stress $(0.37 \mathrm{GPa})$ and pressure change $(22 \%)$.

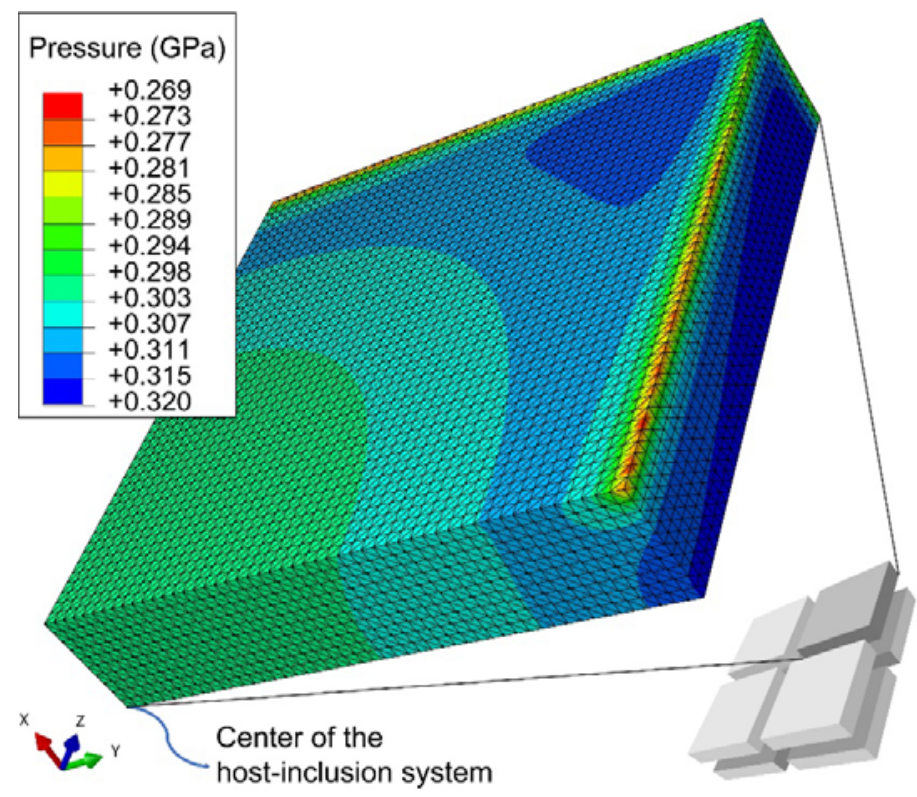

Figure DR3. Pressure distribution calculated in $1 / 8$ of a quartz inclusion (aspect ratio of 1:5:5) in pyrope. 


\section{REFERENCES CITED}

Abramson, E.H., Brown, M., Slutsky, L.J., and Zaug, J., 1997, The elastic constants of San Carlos olivine up to 17 GPa: J. Geophys. Res., v. 102, p. 12252-12263.

Angel, R.J., Alvaro, M., Miletich, R., and Nestola, F., 2017a, A simple and generalised P-T-V EoS for continuous phase transitions, implemented in EosFit and applied to quartz: Contributions to Mineralogy and Petrology, v. 172, no. 5, p. 29, doi: 10.1007/s00410-017-1349-x.

Angel, R.J., Alvaro, M., and Nestola, F., 2017b, 40 years of mineral elasticity: a critical review and a new parameterisation of Equations of State for mantle olivines and diamond inclusions:

Physics and Chemistry of Minerals (in press) doi: 10.1007/s00269-017-0900-7.

Angel, R.J., Nimis, P., Mazzucchelli, M.L., Alvaro, M., and Nestola, F., 2015a, How large are departures from lithostatic pressure? Constraints from host-inclusion elasticity: Journal of Metamorphic Geology, v. 33, p. 801-813, doi: 10.1111/jmg.12138.

Angel, R.J., Alvaro, M., Nestola, F., and Mazzucchelli, M.L., 2015b, Diamond thermoelastic properties and implications for determining the pressure of formation of diamond-inclusion systems: Russ Geol Geophys, v. 56, p. 225-234.

Arimoto, T., Gréaux, S., Irifune, T., Zhou, C., and Higo, Y., 2015, Sound velocities of Fe3A12Si3O12 almandine up to $19 \mathrm{GPa}$ and $1700 \mathrm{~K}$ : Physics of the Earth and Planetary Interiors, v. 246, p. 1-8, doi: 10.1016/j.pepi.2015.06.004.

Ashley, K.T., Steele-MacInnis, M., Bodnar, R.J., and Darling, R.S., 2016, Quartz-in-garnet inclusion barometry under fire: Reducing uncertainty from model estimates: Geology, v. 44, no. 9, p. G38211.1, doi: 10.1130/G38211.1.

Brown, J.M., Abramson, E.H., and Angel, R.J., 2006, Triclinic elastic constants for low albite: Physics and Chemistry of Minerals, v. 33, no. 4, p. 256-265.

Grimsditch, M.H., and Ramdas, A.K., 1975, Brillouin scattering in diamond: Physical Review B, v. 11, no. 8, p. 3139-3148, doi: 10.1103/PhysRevB.11.3139. 
Lakshtanov, D.L., Sinogeikin, S. V., and Bass, J.D., 2007, High-temperature phase transitions and elasticity of silica polymorphs: Physics and Chemistry of Minerals, v. 34, no. 1, p. 11-22, doi: 10.1007/s00269-006-0113-y.

Milani, S., Nestola, F., Alvaro, M., Pasqual, D., Mazzucchelli, M.L., Domeneghetti, M.C., and Geiger, C.A., 2015, Diamond-garnet geobarometry: The role of garnet compressibility and expansivity: Lithos, v. 227, no. 0, p. 140-147, doi: 10.1016/j.lithos.2015.03.017.

Scandolo L., 2016, Thermal expansion of mantle minerals inclusions in diamonds [Ph.D. thesis]: University of Pavia.

Scheidl, K.S., Kurnosov, A., Trots, D.M., Boffa Ballaran, T., Angel, R.J., and Miletich, R., 2016, Extending the single-crystal quartz pressure gauge up to hydrostatic pressure of 19 GPa: Journal of Applied Crystallography, v. 49, no. 6, p. 2129-2137, doi: 10.1107/S1600576716015351.

Sinogeikin, S. V, and Bass, J.D., 2002, Elasticity of pyrope and majorite-pyrope solid solutions to high temperatures: Earth and Planetary Science Letters, v. 203, no. 1, p. 549-555.

Waeselmann N., Brown J.M., Angel R.J., Ross N.L., Zhao J., Kaminski W. (2016) The elastic tensor of monoclinic alkali feldspars: American Mineralogist ,101:1228-1231, Doi: 10.2138/am$2016-5583$

Wang, J., Mao, Z., Jiang, F., and Duffy, T.S., 2015, Elasticity of single-crystal quartz to 10 GPa: Physics and Chemistry of Minerals, v. 42, no. 3, p. 203-212, doi: 10.1007/s00269-014-0711-z. Zhang, Y., 1998, Mechanical and phase equilibria in inclusion-host systems: Earth and Planetary Science Letters, v. 157, no. 3-4, p. 209-222. 